Portland State University

PDXScholar

\title{
Adaptation to dominant society : a self study of a woman of mixed race, black/Indian
}

Helen Marie Camel

Portland State University

Follow this and additional works at: https://pdxscholar.library.pdx.edu/open_access_etds

Part of the Race and Ethnicity Commons, Race, Ethnicity and Post-Colonial Studies Commons, and the Social Work Commons

Let us know how access to this document benefits you.

\section{Recommended Citation}

Camel, Helen Marie, "Adaptation to dominant society : a self study of a woman of mixed race, black/ Indian" (1980). Dissertations and Theses. Paper 3452.

https://doi.org/10.15760/etd.5336

This Thesis is brought to you for free and open access. It has been accepted for inclusion in Dissertations and Theses by an authorized administrator of PDXScholar. Please contact us if we can make this document more accessible: pdxscholar@pdx.edu. 


\section{ADAPTATION TO DOMINANT SOCIETY: A \\ SELF STUDY OF A WOMAN OF MIXED \\ RACE, BLACK/INDIAN}

by

HELEN MARIE CAMEL

A report submitted in partial fulfillment of requirements for the degree of

MASTER OF SOCIAL WORK

Portland State University 


\section{ACKNOWLEDGMENTS}

I would like to thank friends, classmates, and professional individuals who provided insight and direction in my efforts at gathering information and thoughts for this paper.

Secondly, to thank Lyndon Bohanan whose direct feedback, editing ability, and encouragement rekindled my final efforts to complete the paper. Also, to his secretary, Pat Mayhew who painstakenly typed the numerous drafts and final paper.

Lastly, to Dr. Miles who presented me with the original idea and who patiently advised me to the final product.

And, above all, to thank my daughter Leslie, whose unquestioning love and devotion made it all worthwhile. 
TABLE OF CONTENTS

PAGE

ACKNOWLEDGMENTS

CHAPTER

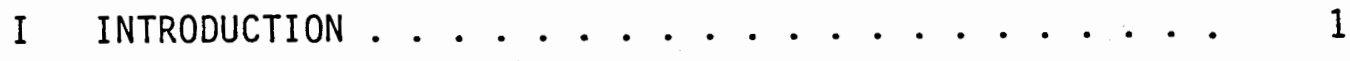

Nature and Aim of Study ........... 1

Background and Setting ........... 3

Self

Mother

Father

Significant Others

Other Female Sibling

Relationships within Family ......... 12

Environment ............. 12

Reservation

Indian/Black Heritage Orientation

Chronology ............... 17

Frame of Reference ............ 17

II CONCEPTUAL FRAMEWORK . . . . . . . . . . 22

Background ............... 23

Inner Influences............. . . 24

Self Identity

Self Concept Development

Outer Influence ............ 33

Birth Order Factor

Power Struggle

Modeling and Punishment 
Dominant Other/Goal .......... 35

Cultural Influences -- Principles of Race . . . 38 Marginal Man

In Group/Out Group ............. 43

Institutional Racism . . . . . . . . . 44

III CRITICAL INCIDENTS ............. 48

Childhood Situation .......... . . 48

Adolescent Situation .......... 50

Young Adult Situation ........... . 55

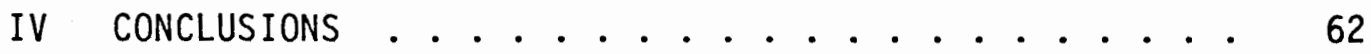

summary ................ 63

Phase I - Unaware ........... 64

Phase II - Experiences Conflict ....... 64

Phase III - More Permanent Adjustment or Lack of Adjustment....... 68

Recapitulations ............. . 77

SELECTED BIBLIOGRAPHY ................ 79 
CHAPTER 1

INTRODUCTION

From the moment of his birth, the human being is the responding subject of a stream of social influences, and if well-adjusted to himself and his social world, he becomes a mature and harmonized personality. The author would like to investigate the conceptual framework of how minorities fit into this definition, that is, non-members of dominant Ang1o society, which includes for the author's purposes, Indian and Blacks. Not only does the individual minority person live within his own culture, but has to adapt and is influenced by the dominant culture as a matter of survival in today's world. Somewhere in his learning process, the individual has to be able to "successfully define the invisible blueprint" which will bridge him between the different, sometimes contrasting, cultures. He will then ultimately prosper as being an end-product influenced by more than one culture, being able to benefit by taking advantage of the "best of both worlds."

\section{Nature and Aim of Study}

This research effort is based on the life and development process which the author has experienced and is currently experiencing. This effort for all intents and purposes, is an individual self-study. "Critical Incidents" have been utilized to develop a sense of understanding for the reader. In reading this paper, one can see that at 
times negative social and cultural situations would cause the author an unusually high level of inner stress, which was not always apparent to the outside world.

To go one step further in relation to racial matters, little comparison can be made between the author and author's family siblings, as much fo author's racial awareness was developed in early adul thood outside and away from the realm of a somewhat sheltered childhood and teen years in the family home. From reflecting back to childhood situations, many mysteries surrounding cultural and ethnic identity were not clearly answered within the family unit. This then led to a cultural identity confusion from which author is currently trying to emerge.

The first aim of the study is to create an insight for the author, who is of a mixed racial background, as to the author's own selfidentity as a person of color, but more importantly, to create a deeper understanding for the author as an individual. Also, an aim is to create in the reader an awareness of the intricate network of influence which culture, family, immediate environment, and society have on the normal personality development of every individual. By sharing somewhat personal and intimate feelings, the author hopes to possibly lessen the anguish of other people of color who might also be victims of a negative cultural and self-concept. By writing, the author has been able to analyze the basis for resultant negative feelings which have continuously preoccupied her inner thoughts. The author realizes the need to be able to deal more effectively with these thoughts and to minimize them to their lowest level in the future. It cannot be said 
that the author will be completely void of these feelings which, for the most part, are permanently imbedded into the individual personality make-up, but hopes to control enotions rather than be controlled by them. The author hopes to further maximize positive personality traits.

It is interesting to note that the author began focusing on the paper from a very negative stance, blaming society as a "whole entity," and not understanding the exact source of anger. Realizing that the mass of information in this state was unmanageable, the author began the process of sorting out and pinpointing issues involved. The author ultimately came to understand that negative cultural issues came to further threaten an already weak sense of ego and self-worth.

The author began the paper feeling somewhat isolated and unique in the situation. Insight has been developed to deal with the inner fears which were, at first, not easy to identify, let alone admit. The normal progression of this paper has been halted, restructured, completion date extended on numerous occasions to coincide with the unexpected, sometimes eruptive growth processes of the individual.

Background and Setting

Self. The author was born on November 5, 1948, in a rural Montana town, being the fifth of fourteen siblings. Her father is a black man who was born and reared in the state of South Carolina. Her mother, like herself and other siblings, are members of the local Indian tribe on whose reservations the family has aiways resided.

Physically, during childhood years, the author was described as being "big for her age," and, unlike the majority of family siblings, has a weight problem. This size separated her from the rest of the 
family and, to some extent, from the peers at school. Being teased and singled out for ridicule, however harmlessly intended, left a negative impression imbedded deeply into the basic cornerstone of her selfconcept.

From these influences the author became overly sensitive to criticisms and became a compliant individual, most of the time sacrificing personal wishes to wishes of others. This, along with being an older female sibling, helped develop a "helper" personality assuming an informal mother role within family hierarchy. Babladel is and Adams (1967) and Wenar (1971) reports that this is frequently a pattern older siblings follow in order to gain parental approval. Reflecting back over life happenings, the author realizes how life patterns have been shaped to conform to wishes or expectations of "significant others." In order to gain acceptance, the author's life was directed by what one "should" do rather than what one wants to do for one's own self interests. An obsession with pleasing an ominous third party became part of the author's personality.

Within the past five years, unresolved racial conflicts have come to the forefront of the author's mind. These negative feelings, which were first focused on a particular segment of the white society, ended in a total disdain for white society in general. The author has been analyzing feelings for basis and clarity. Interpretations of data on the author has stirred many uncomfortable and previously unacceptable facets of personality formation. The author had unconsciously built up an overprotective shield over a weak inner sense of self. Removing these layers was revealing and somewhat traumatic for the author. No 
longer having a protective covering, the author was forced to see in and objective manner as never before transcended.

The author's underdeveloped ego and negative racial identity are delicately and closely intertwined. Symonds (1951) reports that growth in one area cannot be effectively achieved without development in the other.

Motherhood represented some unexpected turn of events for the author. The author had not realized how heavily attitudes and values of parents are internalized by children until the author's daughter stated emphatically, "We don't like seafood, do we, Mom?" (The author had remembered how she had casually mentioned on several occasions this dislike for seafood. No expectations to follow this pattern was ever verbalized to the child. Nevertheless, the daughter had taken this dislike as her own.) Realization materializes that a child ultimately becomes a reflection of its parent.

Although there does not seem to be an end to institutional racism, it becomes an additional responsibility of minority parents to prepare their children for the racism they will encounter. (Note: the author has some reserve in using the term minority to refer to peoples of color. It is used only in reference to the majority or white culture whose way of thinking has previously dominated all institutions of society.) A positive self-image as a person coupled with strong cultural indentifications are the two most important mechanisms that will assure success.

Mother. The author's mother is 59 years old and was 29 years old when the author was born. She is a fu11-blooded member of the 
Confederated Salish and Kootenai tribes (Flathead) of northwest Montana, being born and reared on her home reservation. The mother's religion, like the majority of the local Indian people in the area, is Catholic. Early childhood years consisted of attending a Catholic mission school on the reservation. The mother stayed in school until approximately the eighth grade, after which she was basically on her own, as both parents were deceased.

The author described her mother as a strong person, both physically and mentally. Much time was spent hauling water for household use, including the daily washing of clothes for a family of fourteen, the cutting and chopping of trees for firewood, plus the baking of bread usually every other day.

Both the parents endured physical hardship in the rearing of the children. Driven from the want to feed their large family, at times other-than-legal-means were employed to assure family survival. In this instance, surviving temporarily justified the means. For example, the mother regularly shoplifted meat items to supplement the family's meager diet.

Although the family lived on their tribal reservation, the author expressed a feeling of isolation from close contact with other tribal members. Only in the company of a more traditional "grandmother" did children attend tribal activities. Because a majority of the mother's time was absorbed in daily survival, only a minute amount of attention was directed to concretely instilling a specific culture heritage. As an example, although the mother fluently spoke the Indian language, she did not teach children to speak it. The children's 
knowledge is almost completely void of tribal traditions and customs. The family siblings had never actively participated in tribal dances. The attitude of being proud of these doings was repressed throughout their lives. The children grew up as Indian people, yet with little positive feedback and identification with the Indian culture. An indefinable, almost non-perceptual feeling of being ashamed of any "Indianness" has never been openly discussed nor acknowledged among family members.

The author first became aware of lack of pride in herself as an Indian person when there came about in the country in the early 1970's a resurgence of pride in being Indian. The author then began to question why she had not learned through the years more positive aspects of Indian culture as known by the more traditional Indian people. For a time, the author held anger, i11-placed as she sees it now, against the mother, for not teaching the tribal ways of tribe.

During the 1940's a field of thought was perpetuated by the dominant society upon the newly americanized Indians, of which the author's mother was a student. Purcher (1973) states that in order for Indians to survive or "succeed" in dominant culture, they had to be completely assimilated. Any remnant of "Indianness" was seen as a deterent to the "melting pot" theory. Throughout literature there have been written accounts of incidents of Indians having their hair forceably cut, repressed from speaking their native language, or instances where students were also forceably shipped to boarding schools far from the reservations to "learn the white man's ways" (Purcher 1973). 
No longer are Indian people rejecting their culture in the name of assimilation into white society. As a child, the author had been totally subjected to the mother's way of thinking. This was the mother's way of helping her children survive in the white man's world. The author's growth in racial identity caused conflict within herself. If she were to grow, the author would have to shed a number of ideals which had internalized as a child.

Father. The author's father is a black man who was born and reared in the state of South Carolina. He, like his wife, never spoke of his family or childhood experiences. He entered the service when he was 17 years old, being accepted although underage. He met, married the author's mother, then migrated with her back to her home reservation from. a West coast city where they met.

He, having a sixth grade education, can be called a "self-taught," "self-educated" person. Because of his limited educational background, the father's work history consisted of physically back-breaking work. This almost continual physical exhaustion took its toll in aging him, the premature lines showing in his face. This hard working orientation to 1 ife caused dissention between the parents. The author's mother felt that the father overworked the children, she often being protective of them.

Added to the split of thought between the parents, a somewhat confusing racial issue was imbedded when the mother repeatedly told children that they were full-blood Indian, like she, and were not partBlack. They did understand though that they were Black because their father was Black. The author recalls wondering why the father never did 
respond verbally to the mother's most cruel racial onslaught of slurs she cast against him in her anger. As a result, sibling had seen themselves as Indians, who unavoidably happened to be part Black. Any Black features were frowned upon and downplayed to the maximum. The author remembers being secretly. thankful that she resembled the mother rather than the father, unlike some of other siblings.

The author remembers feeling unexplainably embarrassed when the father was stared at, especially by school peers, although she expressed that siblings had a deep respect for him, bordering on fear, because of his stern ways, The author remembers not being able to explain when questioned by acquaintances as to why sibling referred to the parents as "mom and Henry." Nor did she understand the reasoning why her father pronounced some of his words noticably different than local people. She, at one point, thought it was a speech impediment or maybe a lack of education, not being aware that pronunciation of words differed according to area of the country. The author wondered, inwardly angered, why the father had such a subservient manner when talking to white people, a complete contradiction to his role in family. The author remembers his repetition of "yes, sir," "yes, sir," after what seemed like every spoken sentence, as in the days of slavery when black people treated white people with automatic deference.

The father, although with a limited educational background, was a believer in education. This was never communicated verbally, but rather by his actions, being adament that children attend school regularly. When any siblings played hookey from school, they were usually spanked. The father would abruptly admonish the author's mother who was 
usually approving of children missing school. The author still recalls the look of pride and beaming composure on the father's face when chitdren had good report cards.

The father socialized out in the general community more than the mother, who virtually did not socalize at all and had no adult friends. The father's after-work leisure time consisted of drinking in local bars. He would come home many times with physical evidence of being in a brawl, never openty speaking to children about incidents leading to being called a "nigger," either by Indian or white patrons usually under the influence of alcohol.

Individual employers who came to know the father gained a respect for his integrity as an honest and hardworking person. The majority of discrimination actually experienced by the father, away from bar brawls, was somewhat subtle in nature. He was, if anything and oddity in that most local people had never known, let alone seen, a Black person before the author's father.

Significant 0thers. Author distinctly remembers a now-deceased female relative, a grandmother to the children, in the Indian tradition. This relative usually lived within walking distance from the main family home. She reared the author's older half-sister from early childhood to young adulthood, a role not uncommon for grandparents in the Indian culture.

As a child, the author remembers grandmother as being a "feisty little old lady who had a definite mind of her own." When white people, especially young children would stare at her out of ignorance, she 
was usualiy ready to show obvious irritation at them. The grandmother was the author's main contact with her Indian culture; with her children attended tribal festivities. Non-Indians saw her as different mainIy because she did not speak fluent English, nor dress similar to their general population. This is one of the first concrete experiences that the author witnesses that made her realize that Indian people were seen as different and inferior to the white populations. The author recall feeling embarrassment as being seen as a spectacle.

As the author reflects back over time, she stated now that her grandmother was a proud Indian woman living rather then contemplating her "Indianness." She reacted to the different forms of discrimination from non-Indians as ignorance on their part, and just like children "they don't know any better." In her own non-verbal way, the grandmother was an epitomy of a proud Indian woman.

older Female Sibling. The author's half-sister, who was ten years her senior, functioned in an informal role of being a mother to her. She is important in the sense that she was always supportive and encouraging to the author in numerous life endeavors. The author looked to her when in doubt about capabilities to accomplish a task. Many times after conferring with this sister, the author would come away with an added sense of positive energy, usually going on to complete the task at which she was previously faltering.

of all the outer influence received as a child, the author felt that this older sibling helped develop self-confidence and self-reliance within the author's own abilities. Because of the author's "black 
sheep" posiition within the family network, the older sibling became closer to and over protective of the author.

Although this older sibling had a different father who was an Indian like the author's mother, she became protective and sensitive against racial assaults experienced by her younger part-black siblings. She was ultimately to become the main instrument of concretely insti11ing racial pride.

\section{Ralationships Within Family}

There were specific role formations developed within the family sibling hierarchy. The older male sibling has a dominant position over the younger siblings. This position was partially shared by yet an older female sibling (half-sister) who had always lived in close proximity of the family home. These two strong personalities shared a position of power over younger siblings, and, for the author, were to become subconsious parental role models for the author.

There was a concrete development of male and female roles, the male roles appearing more commanding and valued. While the other children closely followed parental gender role models, there was a sharing of household duties with the younger siblings.

\section{Environment}

Reservation. The Flathead Reservation, home of the Confederated Salish and Kootenai Tribes, was established with the signing of the Hell Gate Treaty of July 16, 1855. The treaty ordained the present reservation and portion of the Bitterroot Valley as the reserve for three bands of Indians, the Flathead, the Upper Pend d'Oreille, and the 
Kootenai. The official name of the consolidated tribes, so organized in 1935, is Confederated Salish and Kootenai Tribes and is one of the seven federally recognized tribes in Montana.

Before the amalgamation of the three tribes, the Flathead people were living to the south of the Bitterroot Valley while the Pend d'Oreille and Kootenai inhabited the upper Flathead Valley. The two tribes in the upper Flathead Valley were unrelated linquistically while the Pen d'Oreille and the Flathead are thought to have migrated earlier from western parts of the continent and were related linquistically to Pacific Coast tribes. Collectively, the Flathead Indians and the Pend d'Oreille were known as the Salish and their time of arrival in western Montana is estimated to be around 1700 .

In 1871, the Federal government issued a directive to the Flathead leader, Chief Charlo to move his band out of the Bitterroot Valley to the Jocko Valley, and twenty years later, the tribal leader losing out to force, moved his followers to the Flathead Reservation near Arlee.

The passage of the General Allotment Act in 1877 accorded each tribal member 40,80 , or 160 acres. Land not homesteaded reverted back to the tribe. In 1910 the Flathead Reservation was opened for settlement to non-Indians.

The total tribal enrollment today numbers approximately 6,000 , of which more than 53 percent live on or near the reservation. The members living away from the reservation reside mainly in the Pacific Northwest and California. 
Since 1960 , to be eligible for tribal enrollment requires having a blood degree of at least one-quarter Salish or Kootenai blood and birth to a tribal member. Today, nearly one-third of the tribal members are under this one-quarter degree level. The number of full-blood Indians have decreased dramatically through intermarriage and death of elderly members to the present three percent.

Today, the on-reservation population consists of approximately 3,150 Indians and almost 16,000 non-Indians. The Flathead Indians and their non-Indian neighbors have lived together for a long time without conflict, although recently some controversies have come to the forefront, such as water rights. For the first time in history, the Indian people are asserting their tribal rights versus state's rights.

The author is somewhat uncertain as to the "real" racial atmosphere on the reservation. As to a general statement, reflecting back when she was a youngster, there seemed to be a subtle racist orientation present but which she did not understand at the time. It was the type that is "hard to detect, but the type that makes one come to believe that as an Indian, one is a second-class citizen."

Without being aware of how this feeling first started, the author came to envision herself according to the negative stereotype of Indiand that she had been subjected to in the education system and through television. The terms depicting Indian people such as lazy, drunken, and savage came to be associated in the back of her mind as being Indian. (Westermeyer 1974). She recalled cheering for cavalry soldiers who gallantly saved fearless pioneers from the hands of blood-thirsty Indians. At that time in the author's life, there was no reason for 
her to question the reasoning behind this graphic portrayal of the Indian in America's history.

As a young adult the author visited a neighboring reservation and was awed by the scene in which Indian people were managing a gas station. At first she could not explain to herself why this situation caught her attention. This was the first time she had seen a person of color, specifically an Indian, behind a counter and operating a business. This feeling is akin to similar responses author has received from her own Indian people who, too, for the first time have had an Indian social worker.

One of the author's first experiences of the effects of racism between people of color was to belittle another by calling that person a "dirty Kootenai." She can remember the insulting feeling previously associated with such a remark. Not until she worked on the reservation did she also realize that the Kootenai people carried an equally negative connotation to being called a Flathead. Somehow a "pecking order" network is instilled among different peoples.

The Flathead tribe has been described as one of the most progressive and prosperous of the seven reservations in Montana. This, in part, is the result of the interactions with non-Indians who settled early on the reservation. Compared to other Montana reservations, only a small portion of the on-reservation population are enrolled tribal members. This long nistory of contact with members of dominant culture has led to the partial loss of tribal identity as compared to more traditional tribes who have less contact with non-Indians. 
The author states that this loss of tribal culture has been a sensitive issue. Here we were doing what we thought we were supposed to do, assimilating according to the dominant society rules, only to find out that we cheated ourselves as a tribe of our rich cultural heritage, according to Indian culture (Bahr, Chadwick, Day, 1972). The tables were turning as other tribes who were once thought to be more backward (according to dominant culture) were now exclaiming, "We kept our culture." Maybe in some ways these tribes "looked down" on our tribe because we have become a tribe of white-appearing and acting Indians.

Realizing the loss, tribal leaders and the communities are actively reinstituting Indian culture as a normal part of the education process, the tribal elders again taking part in the teaching of the young through various tribal programs.

Indian/Black Heritage Orientation. The author was born and reared as basically an Indian person on her home reservation in rural Montana. As the state has a very small Black population, the siblings grew up without any meaningful contact with people of the Black race. Because of this rather sterile environment, the author has come to realize that she has confusing concepts of her "Blackness," again being influenced" by past portrayals of Blacks in the media.

The author would 7ike to note that the mother's orientation for her children were that they were "al1" Indian, this being a step more acceptable than being of a mixed race. Because of the author's living away from the reservation and mainly being seen as a black woman by the general public, some issues have been brought up within the author to which she is still seeking an answer. 
Chronology

This report, or self-study, is set up in accordance to a pattern of individual development, as stated by Stonequist (1937), typical of marginal men. Three significant stages are:

1. A phase when he is not aware that the racial or nationality conflict embraces his own career; (yet not inner conflict, not sensitive about race or nationality because he is not "race conscious."

11. A period when he consciously experiences this conflict.

111. The more permanent adjustments, or lack of adjustments, which he makes or attempt to make to his situation.

Stages frequently correspond to the protected environment of childhood, the widening social contacts and ensuing conflicts of adolescence and the necessary accommodations of maturity; but they also vary significantly with the character of the individual experience and the specific social environment (Stonequist 1937).

\section{Frame of Reference}

The author states that in retrospect and reflecting back on the last ten years of her life that the majority of information which has had an impression on her has been of an informal rather than formal nature. The following narrative may sound like a typical story that everyone experiences in his developmental years. Her experience is somewhat unique due to the aspect of her particular dual ethnic origin which, for her, has created unusual identity confusion with which few people have had to deal. She has felt isolated in her situation even from other members of her immediate family.

Living on her home reservation, the author did not realize that her pathways in life would be directly affected by the fact that she 
was a member of a minority group whose status differs from those members of white society. The non-Indian people that lived on or near the reservation had some racist orientation, but it was subtle in nature and she as a person did not interpret the extent of the racism until leaving the reservation and becoming aware of broader racial issues. When the author talks about the subtleties of racism, the author does not mean to make excuses for what a person is responsible, or where there is an obvious explanation. What the author is talking about is when a person, usually of dominant society, makes a predrawn judgement conclusion about a minority person just by looking at him, according to an "invisible" rating system. Minority people, specifically meaning peoples of color, have been victims of negative stereotypes (Peratti) since the beginning of this great country of ours which has been believed to have been built on the thought of fairness and freedom.

When reading this paper, the reader must keep in mind that at the age of 31 the author is still very much in the process of maturing and developing her self-identity. In ten years this chronicle will probably be only one of the ever-progressing chapters of her personal development. At this time, the feelings expressed are a reflection of the author's innermost thoughts. The author hopes to share a well-developed account of life by recounting and clarifying the past, for herself, but, more importantly, to create a sensitivity to the concept of the "marginal man" (Stonequist 1937). The marginality created by the mere fact of the difference in cultures. What is the effect of living between two distinct cultures on the individual personality? The author feels that she lived a marginal situation within her immediate family, 
but of a different nature which will be described briefly, because it, too, had a negative effect on her developing self-identity. Accounts of how she dealt with seemingly "numerous trials" will be discussed and how each time working them through at her own pace led to increasing self-confidence and strengthening personality formations. From organizing and writing this paper, the author realized that a basic part of her personality has been stunted because of continual dwelling on negative spects of her past. But foremost, a clearer picture has been created for the author in that she has become aware that the root of her "marginal situation" began much earlier in life than she was willing to admit to, or to anyone else. The author, not her race nor family influence, has been her own worst enemy.

By being half-Indian and half-Black, the author has experienced much inner turmoil trying to decipher what the role in life was to be as an individual person, and, secondly, as a minority person many times functioning out of her own culture. Particularly during college and early adult years did the author experience a number of internal growth periods in which she was seeking and inner peace. Before this time, the author received little stimulation as to her self-worth as a person of color or as a person, in general.

As stated earlier in this paper, during her childhood the author was relatively sheltered to racial matters. Along with this, she did not realize nor was she psychologically prepared to deal effectively with the personality changes she was to experience. Even as she entered graduate school, she adhered to a naive "good will prevails" attitude. She had thought that her main concern in graduate school was to 
follow rules and complete academic assigments, and doing that would assure survival of the school experience. She was to experience, in the true sense of the word, a "culture shock." She would come to understand general rules of society which is oriented to members of the majority culture, (Mackey and Blanchard 1972) and to compare and to utilize them according to the sometimes drastically different Indian culture. She had not previously understood that there was a completely different way of thinking as compared to the thinking concepts of majority culture. All "successfull" minorities, as a matter of survival, learn to accommodate themselves within the confines of societal rules, disregarding that which is negative or unacceptable to the concept of their individual well being.

The author's first encounter in this "difference of expectations" of the outside world was when she was a senior in high school. She, like other white students in her class, and plans to go on to college. She had not realized that she had "mimicked" responses of those students she had seen as her peer group. It was not until some years later thay she realized she had embarked on a journey that had little obvious chance of success.

The author's premise of thinking can be exemplified in the following questions: Is there a process in which minority people can retain strong cultural self-image and function adequately within a world influenced by dominant societal standards without falling prey to invisible recist thoughts aimed at making them feel inferior or second-class citizens, as the author has? Second, does a mixed cultural background 
constitute a problem in the sense of rejection of one race by the other? The author feels that society is not consciously acknowledging responsibilities for the "invisible barriers" with which minorities have to contend in order to survive admittance into the "mainstream" of 1 ife that is more readily available to members of the dominant society. One of the reasonings behind this self-study is to create in the reader's mind an understanding and awareness of the "uphill plight" of minorities as to the development of a positive sense of self-identity. 
CHAPTER II

\section{CONCEPTUAL FRAMEWORK}

Social science has developed numerous concepts which are concerned with man's personality development and his adjustment to his immediate environment. In order to help the reader understand influences experienced by the author, a selected review of material will be presented. This includes ego psychology which describes the development of ego and self identity. This is then related to the concept of marginality and the individual's relation to his culture, i.e., marginal man, cultural conflicts, in group/out group status, process of adaption. The author wishes to distinguish influences from within the family (ego, self) and how they influenced the author's reaction to outside societal and cultural issues. The different concepts will be referred to and applied as they depict events and experiences in the author's life. There is the general understanding that no one concept is mutually exclusive in nature but that a number of them are interrelated.

The intent is to dissect the author's life history of experiences in an objective and meaningfur way so as to depict a web of intricate influences which determine personality development. As this is done in retrospect, the author hopes to present her story in as objective manner as possible, in relation to her perception of past happenings.

To avoid confusion, the author is presenting material in the premise that the reader is somewhat familiar with concepts and able to 
qualify a point of view. Books and articles cited can be referred to for additional in-depth reading and research.

\section{BACKGROUND}

The text The Marginal Man by Stonequist (1937) is a main source of information on which to develop a definition by which to base life history. The text will be referred to frequently later in this segment in defining milestones in the author's life, describing the innermost feelings and coping strategies used at each particular point in her life. This sociological concept was first used by Robert E. Park (1928), but was developed by Stonequist (1937), who states:

From his moment of birth, the human being is the responding subject of a stream of social influences. Before he has learned to speak a single word, or experienced the first glimmer of self-consciousness, he has felt the impress of those activities, standards, and objects which make up that complex whole termed culture. With the acquisition of language his mental, social, and physical development expand into new dimensions and he gradually learns consciously to adjust himself to the expectations of his social group. Through unconscious as well as conscious interaction with other persons, he gradually comes to have a recognized place in his particular social world, to plan a career, and to line up to those standards which are evolved out of his experience and doubly rooted in his selfrespect and in the established codes of his social group. If well-adjusted to himself and his social world, he becomes a mature and harmonized personality.

From the definition of the "marginal man" the author is categorizing her life according to three sets of influences, one which develops the personal sense of self-identity as an individual, as a member of a family, and as a functioning member of her social and cultural world. It is safe to say that every human being is influenced by his particular surrounding culture and to a certain extent is a product of their 
environment. All people experience relatively similar growth situations according to normal personality adjustments because we are people with somewhat similar needs and aspirations, such as the need for food and water, the need to feel loved and accepted, and to feel a sense of accomplishment. From this point on in this section concerning concepts, we shall be discussing ego development and concept of self in relation to personality development. The second part will detail how familial identity formations and societal/cultural identifications thus contribute to the persons' conception of themselves.

\section{Inner Influences}

Self Identity. In order to understand the development of personality, we need to delve into some of the intricate networks that contribute to the development of such.

Ego is used to refer to that phase of personality which determines adjustments to the outside world in the interest of satisfying inner needs in those situations where choice and decision are involved. Or, to define ego differently, it is an active process for developing a plan of action for attaining satisfaction from inner drives. The self, on the other hand, refers to the body and mind and to bodily and mental processes as they are observed and reacted to by the individual (Symonds 1951).

Man is not born with an ego but is the product of learning and development. Ego development begins at birth and is a continuous process which is never completed. It may be safe to say that every experience which an infant or child responds with feeling contributes in small quota either positively or negatively to ego development. 
The child develops his ego to the extent that he is given the opportunity to try things out for himself, to explore and gradually to develop methods of adaptation. The ego develops in the self-assertive responses of an active infant to other assertive individuals. The ego cannot be conceived as a static, finished, perfected entity. The essence of the ego is that it shall be an adapting apparatus, constantly mediating between the needs of the organism and the demands of the environment. Ribot said many years ago that the ego exists only on condition of continually changing. As the ego serves its function of helping an individual adapt to circumstances and solve new problems, it consists of ever-changing series of conscious states (Symonds 1951). If ego processes become static and repetitive, they would fail in their task of helping an individual adjust to the constantly changing inner demands of his organism or to the changing conditions of the outside world.

The author would like to refer to some specific developmental areas of ego and self as they directly relate to ther individual concepts to be dealt with extensively in the summary. These aspects, although somewhat a negative orientation, need to be identified in order to pinpoint coping and defense mechanisms used.

In the early part of life, the development of self destroys the infantile illusion of Omnipotence (Symonds 1951), i.e., having unlimited or very great authority (Barnhart 1975). As the distinction between the self and other persons develop, it becomes necessary for the infant to recognize his own weakness in comparison with the greater strength and skill of other persons. Growth of the self seems to require a clearer 
realization of the weakness and littleness of self. Even as the ego increases in real strength and power as the child learns skills which enable him to master his surroundings, so there is at the same time a growth in familiarity with the weakness and limitations of the self.

Because this awareness of weakness in itself is threatening, there is a tendency to project omnipotence onto others so that in a later stage of infancy the parents are looked on as all-powerful and all-wise individuals. This feeling of omnipotence in one's elders may continue throughout childhood and may be dispelled as a greater awareness of reality takes place in later adolescence. Some individuals, however, never outgrow their feeling of awe and deference to the greater wisdom and power of their elders. This projection may extend beyond parent figures to rulers and to anyone who is in a position of authority. By believing in a supreme deity, the individual bolsters himself in the light of his own feelings of weakness, helplessness, and inferiority (Symonds 1951).

In each of these projections, there is also an indentification. The little boy can add to his strength by feeling that his older brother or father is a strong, important, and powerful man. One can add to his own feeling of strength by humbly asserting his own belief in God.

According to Snygg and Combs (1948), the self is found only as the individual defines his relation to the world around him. The specific form which the self will take varies according to the relation of the child with adults, with this opportunity which the social environment provides, with opportunity for language development, with contact with cultural products and symbols, with give-and-take associations with age 
contempories (Snygg and Combs 1948). Gesel finds that a child will set standards for himself typically by 72 months (six years old). A child's attitude toward himself will be realistic if others take a reasoned and sensible attitude towards him, but his concept of himself will be distorted to the extent that others express unfair attitudes about him.

Self Concept Development. A somewhat foreign, although related, thought may add insight. Researchers have found upon administering the Tennessee Self-Concept Scale that the college women who had participated in high school sports scored higher. This suggests that sports may foster self-confidence and identity, especially when they are part of the adolescent growth period. In additional research in differences in self-actualization comparing nonathletic college women to athletic, the athletes were less dependent upon opinions of others, held more growthenhancing values, were more flexible in applying those values, were more sensitive to their own needs and feelings, and were more apt to see people as essentially good, were able to see the opposites and contradictions in life as meaningfully related to each other. Thus, the female athletes were more self-actualized--surer of themselves, their world, and their ability to relate meaningfully to that world.

Sports, then, seem to enhance a general sense of well-being and self-identity. It is not necessarily sports per se that brought about this effect, but the serious involvement and mastery in the activity, backed by parental encouragement (Rahebaugh 1979).

Some investigators have found that the most negative attitudes are expressed about obese people (Gliedman 1979). The stigma attached to being fat is equated to the stigma experienced by inner-city blacks, 
epileptics, or people with cerebral palsy. There are significant changes in expressed attitudes which first appear around age six. Asked about their feelings about six pictures of children--all but one of them disabled--six year olds tended to rank slight facial disfigurement as most acceptable, second only to normalcy. Eight to ten year olds ranked those with crutches and leg braces as most acceptable after able-bodied children, followed by a child in a wheel chair, one with an amputated forearm, one with facial disfigurement, and, finally, an obese child. By senior year, girls set facial disfigurement as least acceptable while boys ranked it fourth out of six in acceptability. (Male and female adults tend to follow the same pattern.) Again, there was a paradoxical finding that race was less stigmatizing than disability, and obesity often more stigmatizing (Gliedman 1979).

A concept of group consciousness or membership is necessary for further development of self. A child has to learn that he is a boy and different from a girl, that he is white and different from a Negro, that he is poor and different from one who is rich. In these perceptions that child is learning to identify himself with a group or groups and these group identifications are intrinsic aspects of the development of personality (Horowitz 1939).

For this reason membership in a group together with awareness of this membership is an integral part of the formation of self. Individuals who live in extreme isolation fail to form adequate percepts and concepts of self. As Hilgard (1949) has said, "the self, as a social product, has full meaning only when expressed in social interaction." Snygg and Combs (1948) point out that not only does the self develop 
by perceiving group differences but also by being sensitive to group expectations. Society expects different reactions from boys and girls, from young and old, from rich and poor, from educated and uneducated, from members of different occupations.

Shifts in attitude toward a person by others are reflected by changes in attitude of the person toward himself. When he is with others who admire him, he feels confident, but when he moves over to a group that is critical, then his confidence wanes. The developing self becomes less stable in the midst of changing and inconsistent situations. In spite of the fact that the perception of the self reflects the way in which the individual is perceived by others and their expressions of attitudes toward him, there is still considerable disparity between the perception of oneself and one's perception of him.

In later adolescence group identification becomes increasingly a factor in ego formation; to the extent that society is cohesive and consistent, it helps to form a strong and integrated ego. On the other hand, to the extent that society is stratified and specialized, it contains forces that are disruptive to ego (Symonds 1951). When society lacks cohesiveness and consistency, children are forced to base their egos on models that are shifting, sectional, and even contradictory. One must recognize that the different cultural groups, each with its different set of standards and expectations into which modern society is split, represent hazards to ego integration. In particular, there is conflict between expectations of an older and stabler society and the newer and more fluid society. In the author's case, there is dissention between the Indian culture and the dominant Anglo society which many 
times has conflicting values accorded to each of its members. Society in general include goals such as cooperative versus the competitive, migratory versus sedentary trends, tendencies toward standardization as contrasted with individualization, and, within the Indian culture, progressive versus traditional. These contradictions are fateful for the strengths and weaknesses of the ego. Where the individual is pulled in different directions, he may find it difficult to adjust to new situations in which his previous tendencies are less appropriate.

It has been said that while frustration and deprivation are necessary conditions for the establishment of the distinction between the self and other objects, they are not sufficient conditions for the establishment of this difference. Frustration initiates search but does not direct search. Previous satisfactions and anticipation of future similar satisfactions direct the individual toward the object of his search. If wish coincides with reality there is a moment of illusion when a bit of experience (a baby taking the nipple) can be taken either as an inner experience or an external reality. So the infant learns to associate outer reality with inner urges (Winnicatt 1945). There are three stages, then, in recognizing and accepting reality. They are:

First State: An attenpt is made to ignore the unpleasant as though it did not exist. The most primitive method of meeting frustration is to attempt a solution in fantasy or imagination and to pretend that the unpleasant does not exist. Fantasy itself has no brakes; fantasy can be brought under control only through the necessity of having to meet frustation imposed by reality.

Second State: To deny the unpleasant. This is a transition stage because the very art of denial at least admits its possibility to consciousness and shows that one is wavering between admitting it and ignoring it. 
Third State: Of facing the unpleasant or mastering it by withdrawal and giving up hope that it can yield pleasure or by attempting to modify the situation so that satisfaction can be achieved. The ego grown out of his conflict between fantasy and reality (Winnicott 1945 ).

With too much frustration and too little satisfaction, ego growth is retarded and reality actually denied for the pain is more than can be borne. For example, in the face of too great deprivation of love, an infant will turn to himself for satisfaction in the form of thumb-sucking or masturbation, and the child who is forced to love only himself prolongs his infancy. On the other hand, with too little frustration there is no differentiation of the self from the outside world, and hence there is no stimulus to ego growth (Symonds 1951). The development of the ego proceeds at a maximum pace, however, when there is more indulgence than deprivation, for indulgence helps to develop the sense of confidence and makes it possible for the infant to tolerate frustration and tension. The synthetic function of the ego helps to control ambivalence and to keep it functioning most adequately. When the synthetic function of ego is weak, then ambivalence may get out of hand. It may, for instance, result in such splitting of the personality that the negative side may function without regulation of the positive side. When hate is not tempered by love, the integration of the personality is threatened. Or, if an individual finds it necessary to displace either hate or love onto another person, he may therefore manage his ambivalence but at the cost of personality integration. The best integrated individual is one who accepts reality and recognizes that the source of deprivation may also be the source of satisfaction (Symonds 1951). 
Identification helps ego expand and broaden. Without a process of socialization, the individual remains narrow, provincial, and limited. Through identification he manages to partake of the different forms of culture around him and participate in it more fully.

Self feelings may be active or passive. One may have the feeling or attitude of self assertion, of confidence, or being in control of a situation, of directing oneself forward in a purposeful activity. On the other hand one may have the feeling of being a victim of circumstances, or being helpless and dependent, of having things happen to one's self over which one does not have much control. Normal living is a combination of these dual feelings of self-direction and helplessness.

A certain degree of self feeling is essential for normality (Symonds 1951). It is normal and healthy for an individual to experience self with a certain amount of warmth, familiarity, and intimacy. Such healthy self feelings is the basis to happiness; without such feelings the individual feels heavy, dead, lifeless, and life holds no meaning or zest. With the mere knowledge of the self, without feelings, the self is experienced as something insufficient and incomplete, an experience almost akin to fear.

Awareness of self keeps pace with expanding ego. The concept of self is determined in large measure by success or failure of ego. It is difficult to separate ego mastery and enhancement of self as they both ebb and flow in parallel fashion. The functioning ego leads to self-conficence, self-assurance, and self-reliance (Klein and Schoenfield 1941). These qualities are the result of having the ability to meet the demands in place as defined by others. When one can function 
adequately so as to meet the approval of others, then he gains selfesteem and self-confidence.

\section{Outer Influence}

Birth Order Factor. Psychology is a continuing labor of trying to identify the major influences upon the life and behavior of human beings, relating to these similar experiences, and approaching rules which are generally applicable. A century of study has evolved guidelines which are partially applicable to everyone. We know that genetic inheritance leaves indelible marks, and that sexual development and gratification are important. Whether parents are loving or nonloving affects a person struggling to maintain, actualize, and enhance his or her personality. Being male or female makes a great difference. Family wealth or poverty also plays an important role. These are a few of the variables which impinge on the lifelong development of the individual.

According to Forer (1976), one such variable--an important one--is birth order, the position into which a child is born within the framework of the family: the first, second, third, fifth, eighth, last, or only child. One's place in the family strongly influences how he sees the world and how he copes with people. This can be affected by being the first or last born, or preceded by a more powerful brother or mothering sister, as an example. Individuals often assume that their particular experiences are unique in that they alone are "so affected" by their life experiences. They are often amazed to learn that people with similar familial backgrounds or make-up share common reactions to this basic family unit. 
In relation to the concepts presented in this self-study, the reader needs to keep in mind and make periodic reference to "role formation." Role is the word we give to a pattern of behavior and attitudes that a person displays in a specific situation which triggers a response (Forer 1976). Through this process of analyzing her life, the author has been able to better understand underlying feelings which beforehand seemed somewhat complicated.

Power struggle. The sibling hierarchy is a little social system in which dominance is exercised by the more powerful. 0lder children are usually physically stronger and play a parent-surrogate role, according to Forer. As adults they are often bossy, as in childhood, especially if they were the oldest among a number of children.

Further, Forer states, out of these childhood conditions develop the ways a person exercises or succumbs to power in adulthood. What has been learned in childhood colors adult relationships, determining whether a person tries to dominate husband, wife, or children, and how the person relates to friends, employers, employees.

Since older brother or sister is often engaged in direct struggle with parents, the younger brother adopts the opposite method of being sweet and good.

If older sibling is compliant--younger sibling is demanding and aggressive. Any later-born tends to manipulate his way around opponent or problems because this was how he was required to maintain and enhance himself in a power struggle with brother and sister.

Modeling and Punishment. Later children often use older siblings as models--if they are of the same sex--finding them a source of sex 
role identification (Forer 1976). If they are of the opposite sexes, there may be a tending to develop opposite-sex characteristics. Sisters with brothers seem more influenced toward adoption of opposite-sex characteristics than are brothers with sisters. If brothers have sisters close in age, their own male characteristics may be intensified, while the sisters often adopt male interests and attitudes. This may occur because male attributes still seem more prestigious in our society.

Not only do punishments and rewards of parents determine how a child feels and behaves in each place in the family, but children themselves reward and punish one another for behavior that agrees with or opposes their own needs. The oldest may reward younger children if they behave in ways that allow him to enjoy the rights and prerogative of his seniority. If a younger sister allows older sister to show how responsible and able she is, the older sister is nice to the younger one. If the younger sister asserts herself, the older one is likely to punish her, in ways ranging from verbal complaints to physical blows. The younger sister may appear subservient to a stronger authority figure, but she also learns to punish the older sister by cajoling an even higher authority figure: the parent (Forer 1976).

Thus, it is the interactions among members of the family which trains each of them to take on certain patterns of behavior and life roles. Each child has certain potentials for enhancing and maintaining himself. One grows to associate these possibilities, in feeling, behavior, and attitudes, with one's role or place in the family.

Dominant Other/Goal

An interesting field of thought was expressed by Arieti and Bemporad (1979) in that people with a depressive personality are on a life-long quest to recover a childhood loss. The phychiatrists contend that "sorrow work", i.e., working through a feeling or sense of per- 
motivated by a Dominant Goal has decided in early adolescence that to regain love, he or she must achieve something great in life: to become a famous actress, to win a Nobel Prize, etc. When they realize that they are unable to achieve their desired goal, they become depressed. Unlike normal people, they are unable to find alternate goals in life. Lastly, women really are depressed more often than men, and the reason is that we still live in a patriarchal society in which women are raised to be dependent on another person (Arieli and Bemporad 1979). Women more often than men have the relation of submission to the Dominant 0ther, who does not have to be a male, incidentally. There are many women who have another woman as their Dominant Other--a sister or a friend, or their mothers.

\section{Cultural Influences - Principles of Race}

Marginal Man. Many minority individuals live and work within the boundaries of dominant society but are also members of a distinct and separate culture. Within this group, how does living in a sub-culture affect their total personality structure? As stated by Stonequist (1951):

An evaluation of personality takes place more easily and spontaneously when the individual is born with normal and human capabilities and lives in a reasonably stable and organized society.

And, in addition:

Tradition and custom then chart the course of his career. The definite limits thus chart the course of his career. The definite thus set may to the modern mind seem narrow and imprisoning, but to the individual concerned they are quite natural and desirable, since he has no other standard by which to make a comparison. He has but one tribal or national tradition to acquire, one language to learn one political loyalty to develop, one moreal code to which to conform, one religion 
to follow. The unity and harmony of his personality: in his sentiments, his conception of himself, and his aspirations, and his style of life.

Thus his personal sentiments will mirror the sentiments of his society, and will be well integrated with the other aspects of his personality. His conception of himself will have a core of certainty paralleling the certainty of his group membership; there will be a minimum of uneasy self-consciousness and sensitiveness. The stability of his sentiments and conception of self will prevent that chronic restlessness which deflects normal ambition into avenues of escape rather than towards realistic goals which have a possibility of achievement. The manner and method of meeting crises and reaching goals--the "style of 1 ife"--will therefore be attuned to adjustment.

There are continual readjustments in any society because of the modern world of economic competition and shifting social relationships. The individual must continually be adjusting himself to these changes. The change might be lesser in stable or isolated societies, but for the most part every individual has to learn how to readjust himself to our ever-changing society. The possibility that he will not do this with complete success is greater than before. Social maladjustment, whether slight or great, then becomes characteristic of modern man (Stonequist 1937).

In further describing the definition of the marginality situation, this can be the individual who has a mixed cultural or racial background, but can also be related to relations of minor groups such as social classes, religious sects, and communities. This person who through migration, education, or marriage, or some other influence, leaves one social group or culture without making a satisfactory adjustment to another, finds himself on the margin of each but a member of neither. He is a "marginal man" (Stonequist 1937). 
The marginal personality is most clearly portrayed in those individuals who are unwittingly initiated into two or more historic traditions, languages, political loyalties, moral codes, or relations. This occurs, for instance, as a result of migration. Migration is so common in the modern world that nearly every land or city is something of a melting pot of races and nationalities. New countries like the United States are only conscious examples of a world-wide condition.

This dualism does not always constitute a personal problem. Man is a plastic or teachable being. He comes into the world with a flexible nature and with multiple potentialities which enable him to fit into the most varied of culture patterns or social organizations. Each group in which he participates requires a special type of adjustment and conformity. As William James once observed, the individual "has as many different social selves as there are distinct groups of persons about whose opinions he cares. He generally shows a different side of himself to each of these different groups." Even the normal individual, therefore, is in a mild degree a kind of multiple personality.

When the standards of two or more social groups come into active contrast or conflict, the individual who is identified with both groups experiences the conflict as an acute personal difficulty or mental tension. He may be compelled to choose between two national loyalties, or only between two minor groups; or either case the situation is the same: the external conflict of the groups finds an echo in the mind of the individual concerned. (Stonequist 1937).

When the cultural transitions and conflicts occur there are marginal personalities. If the cultural differences are of major importance, if they include sharp contrasts in race, and if the social attitudes are hostile, the problem of the individual whose sentiments and career are bound up with both societies may well be acute. His dual connections will then be reflected in the type of life he leads, the nature of his achievements or failures, his conception of himself, and many of his social attitudes and aspirations. He will, in fact, be a kind of dual personality. 
Important as such problems of transition are, they are neither so profound nor so acute as the conflicts which center about race or nationality. For the individual's racial and nationality membership is relatively fixed and permanent, and related to a definite group organization having political significance. His race he can never change, though some mixed bloods do 'pass.' His nationality forms the widest social environment in which his personality develops and unless he separates himself from it when young, it prints an indelible mark. Thus, according to Stonequist (1937), the sense of racial or national identity is one of the very deeply lodged elements in an individual's self.

In external relations also, nationality and what is termed "race" exercise a powerful influence. In this sense race is referred to as those inherited physical differences which characterize groups of people (such as color, hair structure, head form, stature, etc.). In many modern countries society is based directly or indirectly upon the principle of nationality. Other types of groups are subordinated to nationally organized state. Consequently, if an individual is ostracized because of his "race" or nationality, he is automatically excluded from numerous spheres of social activity--from a system of group relationships. This is all the more galling, Stonequist (1937) states, because it is based upon birth or ancestry and not upon personal choice, for the solution is then automatically removed beyond the individual's control.

Arnold Green (1947) criticized Stonequist for putting too much emphasis on culture conflict as the basis of the marginal personality characteristics. Green suggested that group antagonisms and not the 
disparity of cultural values, are the source of personality difficulties. He stated that the persons whose values and behavior most approximate the dominant majority experience the most severe personal crises.

Alan Kerckhoff (1955), taking his cue from Greene (1947) defined the marginal man as one who has internalized the norms of a particular group but is not completely recognized by others as being a legitimate member of that group. Thus, the marginal man is one who is excluded from a group which he has made his reference group. He does not possess a positive framework of thought independent from his dominant group associates, but he does experience the uncertainty of being accepted or rejected by them. Kerckhoff, in using this definition, focused upon a discrepancy as the source of personality characteristics. He suggested that the individual develop marginal personality characteristics when he wants admittance into the dominant group but is barred full admittance.

As expressed in the beginning of this section, the term the "marginal man" was first used as a sociological concept by Robert E. Park (1928). Earlier, Simmel (1950) had developed a similar social type which he called "the stranger." To Simmel, the feature which made the stranger of sociological interest was the attitude of objectivity which he held in regard to the group. The stranger was not committed to the unique ingredients and particular tendencies of the group. Yet the objectivity did not simply involve passivity and detachment. Simmel (1950) states that "it (objectivity) is particular structure composed of distance and nearness, indifference and involvement." 
Park (1928) applied this idea to the European Jew who had come out of a restricted ghetto to participate more extensively in the gentile community. Park described the Jew as the "stranger" PAR EXCELLENCE--"the first cosmopolite and citizen of the world." The Jew became a citizen of the world because he was a cultural hybrid. Park described him as follows:

A man living and sharing intimately in the cultural life and traditions of two distinct peoples; never quote willing to break, even if he were permitted to do so, with his past and his traditions, and not quite accepted, because of racial prejudices, in the new society in which he now sought to find a place. He was the man on the margin of two cultures and two societies, which never completely interpenetrated and fused.

\section{In Group/Out Group}

For Park and Simmel, marginality involved two aspects, values and social ties. There is an inconsistency between the value perspectives from which the marginal man may judge and view the world. If he acts according to one set of values, he is wrong according to the other. There are also inconsistencies in regard to social ties. Demands on time and loyalties produce conflict. The continued loyalties of the out-group challenge his status in the in-group, and the allegiance to the in-group prevents full participation in larger society. The effect of a marginal position is two fold. There is unstable character, but, also and more significantly for Park and Simmel, there is the capacity for new ideas. Since a marginal man has more than one framework of thought, he is not trapped by a single viewpoint and can take an external position in regard to it. 
From a negative stance the definition of the "marginal man" is one whom fate has condemned to live in two societies and in two, not merely different, but antagonistic cultures (Park 1928).

The fundamental notion of Stonequist's study of the so-called "marginal man" is based on the conviction that the individual's personality, while based on instincts, temperaments, and the endocrine balance, achieves its final form under the influence of the individual's conception of himself.

The conception which each individual inevitably forms of himself is determined by the role which fate assigns to him in some society, and upon the opinion of attitude which persons in that society form of him--depends, in short, upon his social status.

The individual's conception of himself is, in this sense, not an individual, but a social product.

\section{Institutional Racism}

In an attempt to understand the "institutional racism" (to be discussed later in the paper) it is best to briefly first discuss the concept of racism and how this field of thought developed in society. Institutions where it was later practiced compose the framework upon which this country was built. Institutions are stable social arrangements and practices through which collective actions are taken (Knowles and Prewitt 1969). Such institutions in American society include educational, economic, political, legal, and medical arenas.

In this introduction to the forthcoming discussion of institutional racism, it is not the intent of the author to place blame upon any particular institution for the intentional or unintentional practice, but 
to restate the time-honored statement that racism is a basic part of all institutions in today's society. Historic racist practices, for example, include the enslavement of the black people and the religious christianization of the Indian people--a mission which was to find its ultimate expressions in ideas of a "manifest destiny" and a "white man's burden" (Knowles and Prewitt 1969). The author chooses to discuss mainly the American Indian and, briefly, include issues relating to Black people because she is culturally a part of each. She was reared as an Indian, but is somewhat distinct from fellow tribal members in that she and her siblings are part Black.

Some form of white supremacy, both ideology and institutional arrangement, existed from the first day English immigrants, seeking freedom from religious intolerance, arrived in the North American continent (Knowles and Prewitt 1969). These immigrants felt a sense of superior religious idealogy over the Indians and felt a self-proclaimed mission to civilize and christianize them. Ignorance of the white man's god was sufficient proof in itself of the inferiority of the Indian, and, consequently, of the superiority of the white civilization.

The mission influence doomed to failure partly because of shortage of missionaries and unexpected resistance on the part of the Indian led to the dismantling of a few programs aimed at christianization. It became clear that conquering was, on balance, less expensive and more efficient than "civilizing."

Thus began an extended process of genocide, giving rise to such aphorisms as "the only good Indian is a dead Indian." It was at this time that ideology of white supremacy on the North American continent 
took hold. Since Indians were capable of reaching only the stage of "savage," they should not be allowed to impede the forward (westward, to be exact) progress of white civilization. The church quickly acquiesced to this redefinition of the situation. The disappearance of the non-white race in the path of expansionist policies was widely interpreted as god's will (Knowles and Prewitt 1969).

From this beginning comes the present day practice of racism in present day society. The English colonists operated from a premise which has continued to have strong impact on American thought: the Anglo-Saxon race is culturally and religiously superior; neither the validity nor the integrity of alien culture can be recognized. (The Indian culture, though native to the land, was considered the alien one.) When it became clear that "Indians could not be saved," the settlers concluded that the race itself was inferior. This belief was strengthened by such racist theories as the Teutonic Theory of Origins, which pointed out the superiority of the Anglo-Saxons. The institution of slavery and its accompanying justification would seem to have been products of the same mentality.

Lastly, the the 19th century America, the Social Darwinian theory of evolution greatly influenced social thought, hence social institutions. Social Darwinists extended the concept of biological evolution in the development of societies and civilizations. Therefore, the nature of a society or nation or race was presumed to be the product of natural evolutionary forces. The evolutionary process was characterized 
by struggle and conflict in which the "stronger, more advanced, and more civilized" would naturally triumph over the "inferior, weaker, backward, and uncivilized" peoples.

The contemporary expression of Social Darwinian thinking is less blatant but essentially the same as arguments used in the 19th century. The poverty and degration of the non-white races in the United States are thought to be the result of an innate lack of ability rather than anything society has done.

Thus, the idealogical patterns in American society historically and presently sustain practices which can be appropriately labeled "institutionally racist." The author wishes to discuss later the institution of an educational system by which minority cultures have been penalized as inferior (Azure 1973). In understanding how deeply racist practices are embedded in the American experiences and values, we come to a fuller understanding of how contemporary social institutions have adapted to their heritage.

Having examined concepts which seem relevant in the author's experience, we turn now to an examination of certain specific episodes, in contrast to general, pervasive and constant influences. Certain events had strong impact and lasting influence beyond others and will be viewed from the conceptual framework of "critical incidents." 


\section{CHAPTER III}

\section{CRITICAL INCIDENTS}

Of the numerous critical incidents which have occurred in the author's life, three situations will help develop an insight.

First, the author will present an incident from childhood, then adolescence, and, finally, adult life in which to better understand the difficulties of a person facing the loss of self-esteem within her immediate family group, peer group, and racial prejudice, as a young adult. Each incident will be presented as a situation together with the resultant impact on the author.

\section{Childhood Situation}

of the predictable long-term experience of the educational system, the author remembers the days when students were weighed and measured. The oddity of the situation is not actually the situation in its physical existence, but the resulting effect it was to carry within the developing psyche of the author.

Upon entrance into the first grade the author weighed 70 pounds, each year after that gaining approximately 20 pounds, reaching the solid weight of 180 pounds in the eighth grade. After the fifth grade the author was larger than the average female teacher and was wearing clothes from the women's department.

"Oh, why can't we get this over with," inwardly prayed the author. It seemed as if one could hear a pin drop, remembers 
the author, as the teacher called her name to go up to her desk for the beginning-of-the-year weigh-in. The author recalls being consciously aware of the loud beating of her heart within her chest and the fact that her face was slightly flushed. A feeling of panic overtook her as an already weighed student tried to peek at her weight while she was standing on the scale, making her face flush even more. The teacher, becoming aware of author's embarrassment, sent the curious student to his desk. Deep within herself, the author recalls having a feeling of being sickly nauseous and deathly afraid of somehow being found out. She was ashamed of herself for being so much bigger than the other students, for the fact that she physically stood out from the rest of her peer group.

The walk back to her desk seemed like eternity, a reprieve coming as the teacher called the name of the next student to be weighed. For the rest of the day the author would avoid any discussion about how much she weighed.

The author learned the process of avoidance techniques of which she was to become a master, learning to side-step confrontations which would call attention to herself. Throughout her life the author developed a negative image of herself, coming to expect rejection. The beginnings of this perception developed around her weight problem. The author began to focus upon what she perceived "others" thought of her, thereby sometimes unconsciously instigating their rejection. This way of reacting to situations carried over into different facets of her life, she becoming oversensitive to any criticism.

The author internalized this very common school situation as threatening to her sense of self and felt rejected by her peers. Any ridicule or teasing contributed to author's self-conscious state. Her image of herself was being shaped by other's negative perceptions of her, becoming somewhat introverted and feeling a deep sense of lonely isolation from her general peer group. 
Author's concerns about her self centered around the fact that she was overweight and a curiosity to her peers because of this fact. This rejection she felt from her peers superseded any negative racial identifications as race was not an issue within her mental framework.

\section{Adolescent Situation}

"Hey you," the author's brother called in his usually abrupt and unemotional manner. Inwardly the author shuddered at the thought that she might have displeased him in some unmeaning way. "At least he was acknowledging my presence, which wasn't always the case," the author ironically mused to herself, desperately wanting a sense of approval from him. He called author in this non-personal way because he, like the author, was too embarrassed to use author's nickname "Heavy" in front of peers at school, and both were not comfortable in using the author's given name. (Note that an older half-sister, understanding the author's feelings, was to develop a less stigmatizing derivative of the nickname.)

What is remembered most poignantly about this situation was the uncomfortable, awkward reactions she had in her older brother's presence, and that she was never accorded the status of having her given name used in reference to her until she was an adult (even through she was embarrassed using it).

Author also vividly recalls the difference in status accorded her brother in comparison to her. The brother who was an academically competent student and a "coaches' dream" for athletic ability, was eagerly accepted into the most elite student peer group at school. It was as 
if his membership in the most elite clique has separated him from even talking or associating with anyone who did not belong to this same group, even if the person was a member of his own family.

At home, this brother was in the most prestigious position, the mother catered to his every need, many times over the needs of the family's younger siblings. The author's most positive role was to be a helper to her mother, which, although important, did not have much prestige. She was never to be self-actualized in her high school situation, often remembering and referring to herself as a "shadow" during this time period.

The author was to develop a case of the "ugly duckling syndrome" in comparison to this older brother. She was sure to fade into the background in school situations so that she would never be in his way for any reason, not wanting to embarrass him in front of his friends. She was outwardly meek, was used to making concessions to please others, has a low level of expectations for her functioning level.

Author remembers an inward conscious feeling of being ashamed, almost apologetic, of being what she then thought of herself as a fat, tongue-tied, introverted younger sister as compared to the status-conscious, popular students and would like to have "hidden in the closet." She saw herself as a lowly person who was not acceptable even to siblings whose perceptions formed author's intimate identity of herself. The older brother was to become, in the author's mind, a symbol of a rigid, disapproving parent who was never to be satisfied in a humanly realistic fashion. 
The author's only sense of mastery was to be as "informal" mother to younger siblings, a role which came to her only by virtue that she was the oldest female sibling within the household (Wenar 1971). Outside a role in the home, the author was not to experience any definite sense of mastery or success from achievements.

Because of the older half-sister's realization that author was sensitive about her nickname and the sister's altering of such name, there developed a close relationship similar to a mother-child relationship. The author felt loved in the sense that this sister was concerned about her feelings. This sister in essence played the role of a "protective" mother to author. She was also to be author's major person of support and encouragement for author's lifelong endeavors. Any positive sense of self was to be developed out of this relationship. Author has become a victim to an overly critical older male sibling which was to have a negative effect on her developing psyche and how she perceived herself. An added turn of events developed as the author became subservient and compliant to older half-sister who had always been an overprotective female sibling. She provided the author emotional feedback as an ultra-sensitive, vulnerable adolescent. Due to lack of experiences to develop processes of self actualization, author's ego was in an underdeveloped state.

It was because of the lack of development of author's personality that she never outgrew the "infantile illusion of omnipotence" (Symonds 1951) giving much authority and power to older siblings to control numerous aspects of her life. The author was conscious of littleness 
or weakness of self in comparison to people who represented authority, easily giving way in power struggles. This helped to justify her mostly unconscious feeling of inferiority. She never developed the habit of speaking her mind or stating opinions, and was more readily apt to agree with the opinions of others.

Within the last few years, author only began to be aware that she carried a strong identification with her brother although in actuality she was afraid of him. In his presence she is constantly expecting a repeat of adolescent situation. Somehow this identification with brother added to author's strength as an individual who had full command over his immediate environment. The author in her own right has never felt in control of surrounding environment but rather abused by it.

Up through high school years, the author has carried an inner picture of total inferiority resulting from sense of rejection in childhood and adolescent experience. Self-identity and self-confidence were never fostered nor experienced in self-actualization. The author was overdependent on opinions of others, always conscious of "what she should do" to fulfill expectations of others. This aspect controlled her life to the point of becoming an obsession.

The author's nickname helped to constantly remind her of a negative stereotype associated with obese people. "Almost all children have nicknames. Some are complimentary; many are not!" Although these nicknames are often accepted by children, their effect on a developing self-concept is damaging (Wells and Canfield 1976). Not only did she see herself alienated from her peer group because of this, but also 
from her family siblings. She began to internalize these "faults" or "imperfections" as within herself not seeing that they might be faults within her perpetrator. She was not to see herself as an unique or important individual. She felt that she did not even have the right to speak her mind or use her real given name.

Author was beginning to perceive subtle differences accorded to sexual role identifications, the male characteristics being more prestigious (Lyles 1975). The author saw the female role as stoic, unregarding, and completely self-sacrificing.

Added to this was the beginnings of support of the contention of superiority of the white race. To be part of the elite in-school clique was ultimately to be a more acceptable person. There were also economic sanctions in the fact that most of the parents in this group were economically stable, being ranch owners, professionals, or businessmen, unlike a majority of local Indian parents who were laborers or seasonal workers, on the complete opposite end of the economic scale. Acceptance into this group was rigid, even among students of the majority culture (Conger 1973). This then becomes a double bind for minority peers who transcend the racial and economic gap.

The author's mother encouraged understandable associations with this elite group of white peers, seeing them as totally acceptable while viewing Indian youth with different levels of suspicion. This was to be interpreted that membership with elite white peers was more acceptable according to mother's standards. Unlike other average Indian children, the author's siblings easily crossed the invisible color 
barriers, their physical prowess and capabilities being their passkey. The family name is synonymous with athletic achievements on the local, state, and national level.

\section{Young Adult Situation}

The final situation helped to solidify the fragile beginnings of her racial identity as she had graduated from high school void of a sense of cultural group consciousness. The author then entered graduate school and was, for the first time, separated from any semblance of a familiar, almost racially sterile, home environment. In this unfamiliar and somewhat foreign environment, she was then to be thrust in the midst of a cultural clash of her racial stock where she was rejected from both sides. In this quest for her cultural self identity came a more appalling consideration, "Where and how does a person of color survive in majority society which has always denied the uniqueness of their subcultural individuality?"

Upon urging from her immediate work supervisor, the author decided to pursue a graduate program in social work. A special program had been developed to train persons of Indian descent as social workers, ultimately to return to work with their own Indian people. This would hopefully fill a void, although the author had an undergraduate degree in social work. By getting involved with this "special" program, the author would gain additional knowledge of how to work effectively with Indian people. Plus, the masters degree would grant greater freedom in employment choices, higher income, and, finally, more status and prestige. 
For most of the first year, the author patiently awaited receipt of long-sought information, after six months increasingly weary of answering the seemingly unending inquisitions of fellow students which centered around her cultural background. (Out of a student body of approximately 200 students, eight students were Indian.) The author, to outside appearances, tried to live up to the expectations of being a "model" student, although not entirely comfortable with the role of spokesperson, a role that was constant nowadays. She has thought that her biggest accomplishment would be to follow school rules and complete academic assignments, all that was needed for survival. The Indian students used to share a sense of humor on how each of them was seen by school peers as consultants on their particular Indian situation. These peers would usually have to take the information at its face value, as they admittedly acknowledged a lack of information on cultures that were different from their own.

The author came to recognize the uncomfortable feelings that she would have when asked specifics about enrolled tribe, as she knew little of tribe's history or culture. She had not been aware of a conscious need to do so. Never before had she seen herself as a representative or extension of Indian people nor had the education system ever focused upon Indian people with a sense of legitimacy in America's history (Farris and Farris 1976). This author, as an Indian, did not know how she felt about a number of subjects presented to her. A positive selfimage for these individuals was not to be fostered within the confines of society-at-large. Inwardly, the author began to become increasingly 
agitated at this constant "brain picking," although not discounting its positive value. She had entered school to learn and not to be seen as a "specimen under a microscope."

The author was now becoming overly self-conscious about personality traits, thinking of herself as being too quiet, not having mastered the art of "small talk" at which the white students were so proficient. The anglo society has a great urgency for talk. "What is being said isn't always the important thing, but that someone is saying something!" (Paul).

In comparison to the white students, her education level was lacking. Awareness developed that she also lacked many of the commonalities of experiences as shared by white classmates, whose income levels were usually much higher. Unlike most school peers, she had come from within the group she was being trained to serve.

The culmination of the first year was that the author was groping for some sense of stability within the school situation, felt guilt over academic legitimacy of being in a school program, and started to see herself as an object of numerous deprivations, this frame of thought previously consciously unknown. Along with this came a sense of being "pushed forward at a fast rate, not knowing where one is going and not knowing whether one really wanted to go." She desperately wanted to retreat and run from the current situation, yet seeing it as an only chance at success. Recurring mental daydreams of escaping back to the safer boundaries of past life, as just one of a number of tribal people on the reservation, became common. This temporary means of mental escape was focused "in her mind's eye" on a familiar Indian person who 
lived a life of being basically uneducated and existing within the more secure confines of a reservation or perhaps on a skid row somewhere. This person would be laughing, drinking, and, basically, just having a good time. This person was not concerned about his future but was just existing from day to day. "He looks happy, he likes himself, and is comfortable in who he is!" When on the verge of giving up this exhausting uphill battle of existing in this dominant society and education institution, the author would temporarily justify possible retreat by saying, "I don't need this bullshit! I'm ok, even if they don't think so." Stonequist (1937) states:

This ambivalence and sentiment is at the core of sentiments which characterize the marginal man. He is torn between two courses. of action and is unable calmly to take the one or leave the other. The unattainable white world or gentile world, to restrict ourselves for the moment, continues to haunt his imagination and stir his emotion. At one moment it may be idealized and longed for; at another moment despised and hated. The other world to which he has been assigned has the same contradictory characteristic: at times it appears as a beloved place of refuge, solace, and recognition; again it may seem like a prison--something cursed and hateful, even shameful.

"Had other tribal people felt so psychologically miserable at being off the reservation for the first time or was it an inherent weakness within self?" author mused.

The author prepared for the onslaught of questions the second year only to find that the students no longer were curious, each going his own way as graduation plans and ending assignments came into focus. Realization began to form that the author's expectations of an idealized education concerning Indians was never to transpire. She felt tricked in some way, although no one was quite willing to tell the 'why' or 
'how' it happened. Mounting confusion and frustration set in as the author fails to complete her research paper. She had "somehow missed the boat" as the academic excellence required for practicum completion was seen as beyond academic capabilities. With underlying feelings of defeat and personal failure, mixed with bewilderment, author returned to her former job. She was temporarily denied access into the system which was to be assured by this professional degree.

During this time period the author began to feel uncomfortable with the fact that she was "different" from the majority of school peers, being constantly reminded of it on a daily basis, yet not knowing who she really was as a person or as a person of color. She was becoming more race conscious, a condition of the marginal situation, and began reacting to persons in terms of color, receiving subtle hints of white domination and superiority (Stonequist 1937).

This school situation was stressful for the author, to the point of being emotionally painful, causing her much depression. Feelings of being "torn apart from within" can capture the emotion felt. No sense of relief could be achieved from this all-consuming pain. In the end, she saw herself as a failure in the eyes of her family and society as she had not "made it," denying vehemently that she had ever wanted to play by its rules.

The author had experienced much internal stress, too much for her fragile ego to adequately handle in a healthy manner. She withdrew further within herself, bearing increasing feelings of inadequacy. She saw the situation as self-induced, totally blaming herself for the failure. 
Attention is repeatedly focused upon each group attitude and the individual's relation to it (Stonequist 1937). The author was selfconscious to an exaggerated extent, looking at herself through the eyes of the other, trying to double guess the other's perception of her, many times finding malice and discrimination where none was intended. McNickle (1968) describes the problem of being Indian, and being obliged to function at two levels of consciousness, for many individuals, reduces itself to this: they are aware that their communities, their people, their kinsmen are Indians and held in low esteem by general society. The young people especially recognize themselves as Indians, but do not want the low status equivalent.

The particular "critical incidents" were selected to give the reader some insight into the personality structure of the individual. The author did not have a positive sense of self, being "put down" in a number of areas of her life. She, at first, felt alienated from peers because of weight problem, to rejection from within family network. The problems of graduate school further accentuated the feelings of failure as a person, regardless of gender, race, or culture becuase of a "dominant goal" not achieved.

Like other critical incidents in the author's life, these do not show dramatic unity of time and place. Each is to be seen in a context of all that went before: under different conditions their impact could have been negligible. Each impacted on the other, for while the immediate situation passes, the memory remains and is evolved by subsequent experiences. 
We are now at the point where we can draw together the concepts and facts to form a more generalized picture, bearing in mind the social work concept that each person is preeminently unique. 
CHAPTER IV

\section{CONCLUSIONS}

Self study is a form of case study, long a tool of social work for the better understanding of the problems and persons we want to deal. Self study lacks the proper controls for science, but may be useful in the testing of assumptions or theory, raising questions about the interaction of variables, and formation of new hypotheses. The interplay of subjectivity and objectivity is a subject of interest in self study, and from an accumulation of such studies are the data from which both refinement of practice and valid generalizations arise.

As professionals know, it is a painful, even dangerous, process to dredge up the past, to renew buried hurts, to expose defenses. Reading the literature was fraught with dreaded parallels in the author's own life. Interviewing relatives and friends in the quest for authenticity confirmed fears, layed bare self-serving errors and uncomfortable naked truths. More than once the project was at the point of abandonment.

Self study includes self-analysis, self-comparison with theory, and other cases. It thus initiates a therapy, a significant change of perception, and different means of adjustment. A new critical incident is created. As this happened, each time, a rewrite of the entire paper was necessary, with less concrete detail, different, and fewer incidents of more underlying importance. 
This chapter on a summary and conclusions thus should be seen not as final, but transitory. The rest of the chapter will best be seen not as an organized recapitulation, but almost as a flow of present concerns and reactions commingled as our inner lives are, with memories, concepts, and unresolved feelings.

A note of explanation is due at this point. Except for Chapter II and the present section, the rather awkward use of "the author" has been employed in dealing with subjective matter. Use of the reflexive was too remote, use of the first person to poignant and not self effacing. Without this crutch, even what follows could not be put into words.

Lastly, the overall idealism of a graduate student, a woman, the cultural conflict, and clash of racial stock was more than the author could comprehend at a given time, and how it was happening. The mental stress and burden that an Indian/Black woman of reservation background, with low self-esteem and confidence, only added to the frustration of the writing.

\section{SUMMARY}

Looking at the completed self-study, the author feels now more self-realized and positive than at the beginning of the writing. The third critical incident caused the author a crisis which she had to resolve, in order to give her more in depth into self. The stereotyping and cross-cultural misunderstanding was accepted as true by the author, who now looks at those methods as to what they are in actuality, according to Stonequist's (1937) pattern of individual development. 


\section{Phase I - Unaware}

In her childhood years, the first critical incident occurred to develop and reinforce the concept of low self-esteem and lack of confidence of a positive self-awareness. Allowing the author to become overweight led to her being "put down" by her peer group.

The second critical incident helped to develop al ienation from immediate family. This rejection deeply scarred the author's psyche, even to present day functioning. In addition, the non-understanding of the rejection and the feelings of rejection in high school by peers and family caused continuing anxieties for the author as a highly educated, single parent in industrial society, many times without adequate support systems so important to everyday mental health.

Phase II - Experiences Conflict

The author faced many difficult situations in education and realizing the extent of institutional racism to which she had been subjected stymied her in graduate school. This new perspective brought to the forefront a "questioning" period in which many formerly unaceptable issues surfaced. With this came the unsureness of acculturation process that would be required of her as a professional social worker.

In the five years before entering graduate school the author had developed a sense of pride in "Indianness", a thought that previously laid dormant, now only to be seen as a representative of and out-dated relic of the past by members of dominant culture. She had made Indian people her primary reference group, al though never before seeing it as a priority. Thus, the author was "free" of any limiting con- 
straints that might have been previously established. Disbelief and anger set in as realization forms that she is bound by the majority culture's constraint on minority peoples.

From talking with school peers and listening to conversational trends the author concluded that a consensus of thought was that expectation levels required from graduate students were lax for the Indian students, in comparison to white graduate students. A paternalistic condescending attitude seemed to abound. The author had not understood the differences of expectation levels and how they applied to her as a minority person. Much of the classroom information still did not apply to social work with Indian people (Lewis and Man Klung Ho 1975), (Good Tracks 1975) although the author was expected to incorporate the anglo's interpretation of social work methods which are sometimes hard to apply to tribal systems on the reservation level. Ladner's (1973) book was to describe an insightful article about black students experiences in graduate schools which clarified some thoughts for the author.

An outlying issue confronting the author, too, was the discrimination experienced from local Indian people who were seeing her as black. The same rejection was expressed by black people who were not seeing her as black, as she had not lived the "black experience". The author was being rejected from her two cultural backgrounds and was not seen as a fullfledged participation member of mainstream society for which she had fully "paid her dues", in in-group and out-group loyalties, values, and social ties being questioned. 
On one side, she was wanting to be accepted by her primary groups, yet not wanting to totally choose between either. On the other side, within the pecking-order which discrimination sets itself, the author knew it was somehow more acceptable to be an Indian rather than black, by societal standards. Many racist people have expressed overt hatred for black people, yet standing-in-awe of Indian people, covertly not acknowledging or caring to understand his plight. Covert racism is no less destructive to human 1 ife than overt racism no acknowledged as an actuality (Ladner 1973). For this, the author wore her blackness "on her shirtsleeves", so to speak, constantly on the look-out for reactions which could be termed discriminatory, needing reassurance that she was accepted. The author fluctuated from being a member of the Indian world to being a member of the black world. This divided loyalty and ambivalent attitude, too, typify the fluctuating and contradictory opinions of the marginal person. She was in the position of having to choose between national loyalties, never completely fitting into either (Stonequist 1937).

As she had both Indian and black features, her nationality to onlookers was sometimes confusing. Being many times an unintended audience to black jokes, the author was sure not to conceal her black heritage, avoiding possible embarassment of being rejected. Aggressively declaring national origin again is a characteristic of the Stonequist's "marginal man."

In the back of her mind she was yet not wanting to be part of this ominous, foreboding person, so disliked in his obscurity, this 
situation portrayed even in childhood. The author could not yet admit the rejection of her racial identity, perceiving the rejection as wholly from outside her being, coming to see herself as somewhat of a "stranger" (Park 1928).

The author believed that life had to offer her identical benefits to members of white society, as past 1 ife was comparatively void of any acts of discrimination except in an unrecognizable level. The author was caught off-balance in a game whose rules she did not fully understand, and whose dealers were not willing to admit that a game was even being played!

Frustration mounts as the author becomes caught between two worlds--one willingly left behind on the reservation and the one she was now reluctantly opting to enter. Life was viewed as chaotic. The author reflected, "Hadn't I followed the step-by-step blueprint to success?" Becoming overly educated and ambitious for the everyday pace of reservation life, she was seen as an oddity by white school peers, cultural nationality foreshadowing presence. High aspirations had evolved her into a "lost soul" with no home base to which realistically to return. The author saw herseif as maladjusted to the dominant culture because of her minority status, also maladjusted to the Indian community because of internalizing a non-Indian education and values (McNickle 1968, Peretti 1973). Although her education was not rejected in essence, there were cultural ties which were to be forever broken. To her tribal people she had become anglicized, to be forever set apart from them, this being an unavoidable side effect of the 
educational process. There were few professional Indian people with whom the author could share or vent work-related problems; therefore, little or no support systems were available on the reservation level.

As an educated, independent woman, men idealized, yet were intimidated by her. Not comfortable with this reaction, the author developed a habit of not acknowledging being educated, as she did not want to jeopardize her acceptance in this particular situation.

On the other hand, the author came to see herself as "more successful" and berate what is termed "blanket Indians" who chose to remain on the reservation, appearing for all intents and purposes without any incentive to do for themselves. She began seeing them "through the eyes of the dominant culture" and not as the victim of "casualties of change" as many times they were (Peretti 1973).

The author was forced to recognize for the first time the fact that pathways of her life were to be directly affected by her membership in two minority groups, whose status differs from that of white society in general.

\section{Phase III - More Permanent Adjustment or Lack of Adjustment}

A year passes, the author becomes disenchanted in current work role, decides to return to graduate school to complete her degree. Her previous failure was always a sensitive issue, not being acceptable to her realm of thinking, having sacrificed much personal happiness only to end up "empty handed."

Resentment and anger begin to take hold as the author analyzes past happenings, now seen it from a more removed perspective. Where 
she once saw it as a total matter of an inner personal deficiency, she began to focus it in relation to the societal and educational system, seeing the victimization which took place. Thinking that she has always "played the game by society's perscribed rules," only to see that the rules were meant for members of the majority culture only.

In this present state of mind the author was consuming a majority of her mental energy in the combined negatives of a number of situations:

(a) A number of practicum project topics were reviewed, to no satisfaction of author. (b) Indian project director resigned, leaving author with a sense of being abandoned in a "no man's land" of graudate program. (c) The graduate school did not appear to have the genuine interest, knowledge, or respond to the Indian students' "special" needs, providing only superficial "lip service" rather than a legitimate, valid program which program students would develop expertise when working with Indian people. (d) The author entered into personality destructive relationships with men, seeking the stability she had been told they would provide. (e) The author decided to leave dissatisfying employment and social work practice with Indian people altogether, questioning the viability of existing programs. This caused a financial upheaval as she became financially unsure.

In the beginning, the author's personality changed from a passively aggressive personality to a more assertive, verbalizing personality. She directed her anger at white women as the direct representative of white society (her exact opposite), white society in general (who has historically treated minorities with disdain), and the educational system (which had done a thorough job of discrediting the culturally different peoples).

The author felt active dislike for herself as being a willing participant in this plot aimed as discrediting selfhood. Recurring fears of failure, supported by angry feelings became misdirected and uncontrollable, governing her every move. This, coupled with low self= 
esteem, contributed to the most emotionally disruptive period in her life. From this came a survival instinct, knowing that she was losing control of her life, realizing that if direction was not changed, failure was inevitable.

Within this frame of mind the author began self-study, not only to a complete course of study, but at first to retaliate against a system that she once saw as causing her much emotional pain, her ambivalence getting out of hand. Frustration compiled as her inner survival mechanisms set up roadblocks to cloud her efforts at selfunderstanding. As her ego strengthened she would be able to better incorporate and articulate changes occuring within her personality, now able to sort out inner feelings with some sense of structure. The progress of the paper was directly dependent upon her inner mechanism of self-acceptance. As in the beginning, the natural individual introspection of the graduate school experience was viewed as a personal affront by the author, aimed at destroying any semblance of selfhood. When the stress became too great, she retreated to a safer environment to reflect and ponder recent events in life.

The author entered graduate school unaware of the depth of forthcoming educational experience and how it would completely transform her sense of personal and racial identity into more concrete form. Perhaps if she had understood at the time the total ramifications of the adventure, she might not have been the naive, idealistic participant. The author stood, two years after the original expected graduation date, an explosively angry reactionary who was literally crying and cursing a 
system that she saw as psychologically abusive. At some point within the episode sanity seemed to be leaving her.

The author was her own worst enemy. Life situations had taken their toll, she being a prisoner in a jail of her own making. The author's very act of denial of investigating weaknesses of character produced stress--so much that it turned to anger, overcoming her as she failed to accomplish her goal. Acceptance of self was tied into achieving high aspirations and pleasing others, which ultimately directed life, over the author's personal wishes. Her past accomplishments camouflaged a false sense of confidence, which wained as she was out of adjustment in the new environment.

The author, after having been criticized and "put-down" as a child and youngster, realeased pent up anger and resentment on this new institution that blatently surfaced these hidden negative feelings. Although legitimate and easily justified in reality, the author overreacted to the extent that the emotions were out of control. The negatives of society controlled her every thought, disrupting even personal. life. Numerous defensive processes and rationalizations were employed to protect her sense of self, all mental energies being consumed for protection of her status. She did not want to become aware of the then unconscious motive to avoid. As these negative aspects of self were formed during childhood, they threatened the very core of her identity.

Within the confines of the home reservation, the author did not have to face the consequences of racism in the "outside" white society as an identifiable sense of racial identity was ignored, underdeveloped, and confusing. Negative associations to her two cultural groups pervaded 
her deep inner thoughts as she had been influenced to the anglo way of thinking, a direct result of the education system, this fact being unacceptable in this form. The author was caught between their rejections and white society's rejection of her, not able to accept this presumably lowered status.

The author is acknowledging the fact that she unknowingly set herself up to fail, relishing in the somehow deservable pain; also, being in a state of awe on how she could have handled the foregoing mental assults and turbulence. She was not performing well in a graduate school program although too determined to completely quit as her acceptance of self was closely tied with its success. She had a habit of setting up high ambitions in comparison to her average academic ability and low-income background, her tribal background providing educational monies and special programs enabling her entrance into competition with students of middle class society.

Reacting to a number of bad choices in personal relationships contributed to poor school performance and the author was unable to effectively utilize advice or direction from school personnel. Graduate school was, at first, too much frustration with too little satisfaction, its outside demands too much for the author's ego to handle. Her ego growth was retarded and reality denied for the pain of it was more than could be handled in its present state.

Under the perceived provocations, the author felt herself to be less worthy and frustrated, becoming more critical and fault-finding of others. Feeling like a total failure, the author was consumed in self- 
pity as disintegrated school and life situations fell apart, she blaming everyone and everything for personal unhappiness, yet not really knowing the underlying basis.

The author had come to realize that her life was controlled by wanting to be loved and accepted by important people in her life. She had taken on accomplishment she felt met their approval. As this latest goal could not be accomplished, her selfhood as a person was threatened. She became disenchanted as family lost interest in her plight because of time and distance. She came to realize that much of her personal life was sacrificed pleasing these "important others," these goals being directly influenced by white middle class values, she becoming shocked from within, and secretly incensed at the older female sibling whome she could "never satisfy,"

As the author's ego was strengthened, she began to experience increasing anger, whereas she had before passively accepted poor treatment. The author withdrew contact from family members hating them for their perceived alienation, their totality as a group seen as an authoritarian, unloving parent.

The author began to see how the instilling of a lower sex role for women had contributed to her non-acceptance of self as a truly independent individual. Society is responsible, making her feel secondary and cuasing her to see self with some repugnance, to the more prestigiousappearing male role. She had inwardly envied, yet hated this male role that had never been supportive, only recently coming to the understanding that she could be strong within herself. While still not comfortable with role differences, the author has learned that her fears and 
feelings of inadequacy as a woman have a factual basis, today's society being both racist and anti-feminist (Lyles 1978). The women have a societally-prescribed place--in the home--and acceptance elsewhere is limited. To the author, nothing can be more handicapping than being an educated female, single parent, of two cultural minorities, and functioning out of culture by white societal standards.

The position of sibling hierarchy has had a direct effect on the personality formation of an individual and each position has particular problems. Talking over her negative reactions, she was not able to realize that other family members also had suffered equally serious alienations within the family network, some reacting to her as she had reacted to older siblings. Her relationship with older siblings had been formed within normal patterns of sibling hierarchy, the powerful and overbearing personalities of older siblings temporarily stunting ego development. Insight comes that no one is without any problems at all, each having some insecurities at times.

The author's change in attitude about self led to a change in attitude about others, at the time of this writing the author is able to accept her self more. With this the author lost her need to compare herself to her brother in a symbiotic relationship in order to accord herself a "stronger" personality. This maturation process and inner reflection led to confidence in her own abilities and judgment. Greater self-approval and self-esteem lessened her need for approval, helping her to move from a position of dependence upon approval of others to reliance upon own inner values, this being a major step in psychotherapy (Symonds 1951). 
The author surrendered her anger to a more forgiving, less damning attitude toward the world and the people in it to assure strong mental health. She became more sensitive to self needs and better able to accept weaknesses in comparison to strengths, resulting in a more give-and-take attitude, less threatened by sense of perfection. No longer does she need overwhelming approval for sense of love and acceptance. But the author admits that she is sensitive to opposing opinions, her sense of self-confidence dwindling in abrupt confrontations. Now the author does not see herself totally in the eyes of others, but more from within self.

The time of reflection and self-indulgence in compiling information for this study helped to develop confidence, making it more possible for the author to better tolerate frustration and tension. The author's growing understanding created a sense of peace, she being now able to verbalize and pin-point past immaturities even at this writing.

During her two years of graduate school, the author has a problem of dealing with racial identity as she did not have a sense of personal identity to hinge upon, plus the fact that she was psychologically immature. Race was a problem until a definite sense of self was developed, as her group membership increasingly became integral to her developing sense of self. She had at one time thought that her problems were totally from without, not wanting to admit that they might be from within. Being oversensitive to her mixed cultural background, this renewal of identifications helped broaden her sense of racial status, coming to a more acceptable state of mind. The author no longer sees race as a problem, although she feels some disparity between the author's 
perception of self and others' perception of her. She is vulnerable to the non-acceptance from blacks and the rejection from Indians. The author wanted to deny Erickson's (1950) universal precept that minority cultures carry the same racial stereotypes of each other that while society has of them, both being by-products of society.

With some heart rendering resignation, the author acknowledges an everpresent continuing racial problem, not in the minority's situation in particular, but in the majority culture's negative non-acceptance of them. The majority culture will forever dominate and profess cultural superiority. As the present situation will never change, minorities who, like the author, hed "bought into this way of thinking" will continue to feel maladjusted, that is according to majority culture's societal standards.

The minority person's biggest defense of similar brainwashing of these negative feelings is the understanding of the structure of racism in the majority society and how to survive without being psychologically beaten by it. Positive cultural identifications are important safeguards to safeguard the individual's sense of self. No one can alter their nationality or cultural origins, but only alter their reaction and relation to it. A healthy position is learning how to function within one's own culture and dominant culture both, coming to an acceptable middle-point, and being able to take advantage of the positives of both, in an every process of cultural adaptation with is not static.

In essence, minority cultures have never been allowed to vent, or expected to be angry at dominant society, regardless the legitimacy. This type of anger, if released in a negative manner, can be counter- 
productive, and possibly cause the anger to be turned back on the victim without making the original perpetrator accountable. This reaction can further punish the victim and lead to his instability. A lack of understanding about such anger, and positive solutions to their remedy, have been perplexing members of both minority and majority cultures often leading to needless antagonisms between them.

For the author, the graduate school situation brought to a head a number of unresolved personal and racial matters, strengthening the total fabric of her being. The author has since taken reasonable control of her circumstances, concentrating her mental energies in a more realistic manner, and exploring in depth the multilateral roles which she is to forever possess. Because of the personal growth she has experienced, she is better able to objectively help others who might be experiencing similar problems. As a social worker, she is becoming more confident and self assured about inherent abilities because of recent insights.

\section{RECAPITULATION}

Thus, it can be seen that in addition to the normally expected problems, frustration, and adjustments, the author was faced with racial rejections, feelings of inadequacy, actual inadequacies, and problems arising from the failure to come to grips with factors creating maladjustments. This had led the author to a feeling of a loss of control over her environment. She was marginal in the sense that she was of mixed cultural ancestory, migration status, social class status, educated female, traditional versus progressive. The author was an individual 
functioning completely out of her original culture while not completely aware of her cultural uniqueness in its entirety. While most people, especially students perhaps, have serious problems to overcome, sometimes as in the author's case without proper guidance, minority persons face the additional burdens of rejection and feelings of rejection, and the marginal person even more so, for he has no place to go. The author was consumed by feelings of guilt, deprivation, and resentment in which she could not get any help in analyzing, less sure of how she could have been helped.

At the onset, a social worker can begin a relationship with a marginal person with the expectation that the person is struggling to cope with handicapping problems of cultureal transitions, or conflicts, and adjustments, usually poorly understood even within the person themselves, and not evident to others.

This self-study has been a difficult undertaking, its progression determined by individual's growth pattern. To go back over all the hurts and failures was emotionally fraughtful. How much could have been avoided, with understanding guidance, with a conceptual understanding of what was happening and of alternatives. If this study has any value, it is to help the professional in human relations to understand what is going on in the lives of struggling minorities and reactions not only to external appearances, but what is going on beneath the surface. 


\section{SELECTED BIBLIOGRAPHY}

Books

Babledelis, George, and Adams, Susan, The Shaping of Personality. Englewood Cliffs: Prentice-Ha11, Inc., 1967.

Bahr, Howard, Chadwick, Bruce, and Day, Robert, Native Americans Today: Sociological Perspectives. New York: Harper and Row, Inc., 1972.

Barnhart, C. F., The American College Dictionary. New York: Random House, 1975.

Briggs, Dorothy Corkill, Your Child's Self-Esteem. Englewood Cliffs: Doubleday and Company, 1970.

Canfield, Jack, and Wells, Harold, 100 Ways to Enhance Self-Concept in the Classroom. Englewood Cliffs: Prentice-Hall, Inc., 1976.

Conger, John Gameway, Adolesence and Youth. New York: Harper and Row, 1973.

English, 01 iver, and Finch, Stuart, Introduction to Psychiatry, New York: W. W. Norton and Company, 1964.

Erickson, Erick, Childhood and Society. New York: W. W. Norton and Company, 1950.

Forer, Lucille, Birth Order Factor. New York: Pocket Books, 1976.

Kaplan, Bert, Studying Personality Cross Culturally. Evanston: Row, Peterson and Company, 1961.

Knowles, Janis, and Prewitt, Kenneth, Institutional Racism in America. Englewood Cliffs: Prentice-Ha11, Inc., 1969.

Ladner, Joyce A., The Death of White Sociology. New York: Random House, 1973.

Prucher, Francis Paul, Americanizing the American Indians. Cambridge: Harvard University Press, 1973.

Snygg, Donald, and Combs, A. W., Individual Behavior. New York: Harper and Brothers, 1948. 
Stonequist, E. V., The Marginal Man. New York: C. H. Scribner and Sons, 1937.

Seward, Georgene H., Psychotherapy and Culture Conflict: The Community Mental Health. New York: Ronald Press, 1972.

Symonds, Percival M., The Ego and the Self. Westpoint: Greenwood Press, 1951.

Waddel1, Jack 0. , and Watson, Michael, The American Indian in Urban Society. Boston: Little, Brown, and Company, 1971.

Articles

Arieti, Salvaro, "The Power of the Dominant Other," Psychology Today, April 1979, pp. 54-58.

Azure, Denis I., "Indian Children of Canada: Educational Services and Mental Health," Child Psychiatry and Human Development, Fall 1973, pp. 44-52.

Chapman, D. W., and Volkman, J., "A Social Detriment of the Level of Aspiration," Journal of Abnormal and Social Psychology 34 (1939): 225-238.

Farris, Charles E. and Lorene S., "Indian Children: Struggle for Survival," Social Work, September 1976, pp. 386-389.

Gliedman, John, "The Wheelchair Rebellion," Psychology Today, August 1979, pp. 99-102.

Good Tracks, Gimm G., "Native American Non-Interference," Social Work 18 (November 1973): 30-34.

Green, Arnold W., "A Re-Examination of the Marginal Man Concept," Social Forces 26 (December 1947): 167-171.

Hilgard, E. R., "Human Motives and the Concept of Self," American Psychologist 4 (1949): 374-382.

Horowitz, Ruth, "Racial Aspects of Self-Identification in Nursery School," Journal of Psychology 7 (1939): 91-99.

Keickoff, Alan, and McCormick, Thomas, "Marginal Status and Marginal Personality," Social Forces 34 (1955): 48-55.

Klein, G., and Schoenfield, W. N., "Influence of Ego Development on Confidence," Journal of Abnormal and Social Psychology 36 (1941): 249-258. 
Lewis, Ronald G., and Man Kueng Ho, "Social Work with Native Americans," Social Work, September 1975, pp. 379-382.

Lyles, Barbara D., "The Black Woman: Person or Non-person," The Crisis, May 1975, pp. 163-166.

Mackey, John, and Blanchard, Evelyn, "The American Indian," National Rehabilitation Association, Washington D.C., 1972.

May, Phillip A., and Dizmang, Larry, "Suicide and American Indian," Psychiatric Annals 4 (November 1974) 11: 22-28.

McNickle, D.Arcy, "The Sociocultural Setting of Indian Life," American Journal of Psychiatry 125 (August 1968) 2: 219-223.

Park, Robert E., "The Human Migration and the Marginal Man," American Journal of Sociology 33 (May 1928): 881-893.

Paul, Alice, "Cultural Aspects that Affect Indian Students in Public Schools," University of South Dakota (unpublished paper), pp. 10-12.

Peretti, Peter, "Enforced Acculturation and Indian-White Relations," Indian Historian, Winter, Vol. 6, pp. 38-51.

Rohrbaugh, Joanna, "Feminity on the Time," Psychology Today, August 1979, pp. 30-42.

Simmel, George, "The Stranger." In The Sociology of George Simmel, pp. 402-408. Edited and translated by Kent $H$. Wolff. New York: Free Press of Glines, 1950.

Westermeyer, Joseph, "The Drunken Indian: Myths and Realities," Psychiatric Annals, Vol. 4 (November 1974) 11: 22-28.

Winnicott, D. W., "Primitive Emotional Development," International Journal of Psychoanalys is, 26 (1945): 137-143. 